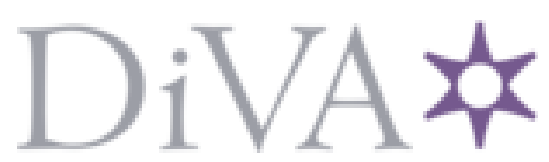

http://www.diva-portal.org

\title{
Postprint
}

This is the accepted version of a paper published in Applied Physics Letters. This paper has been peerreviewed but does not include the final publisher proof-corrections or journal pagination.

Citation for the original published paper (version of record):

Yao, M., Cui, W., Xiao, J., Chen, S., Cui, J. et al. (2013)

Pressure-induced transformation and superhard phase in fullerenes: the effect of solvent intercalation.

Applied Physics Letters, 103(7): 071913

http://dx.doi.org/10.1063/1.4818909

Access to the published version may require subscription.

N.B. When citing this work, cite the original published paper.

\section{Se RoMEO/SHERPA}

Permanent link to this version:

http://urn.kb.se/resolve?urn=urn:nbn:se:umu:diva-81012 


\title{
Pressure-induced transformation and superhard phase in fullerenes: The effect of solvent intercalation
}

Mingguang Yao, ${ }^{1}$ Wen Cui, ${ }^{1}$ Junping Xiao, ${ }^{1}$ Shuanglong Chen, ${ }^{1}$ Jinxing Cui, ${ }^{1}$ Ran Liu, ${ }^{1}$ Tian Cui, ${ }^{1}$ Bo Zou, ${ }^{1}$ Bingbing Liu, ${ }^{1, a)}$ and Bertil Sundqvist ${ }^{2}$

${ }^{1}$ State Key Laboratory of Superhard Materials, Jilin University, No. 2699 Qianjin Street, Changchun 130012, People's Republic of China

${ }^{2}$ Department of Physics, Umeå University, 90187 Umeå, Sweden

a) Author to whom correspondence should be addressed. Electronic mail: liubb@jlu.edu.cn

\begin{abstract}
:
We studied the behavior of solvated and desolvated $\mathrm{C}_{60}$ crystals under pressure by in situ Raman spectroscopy. The pressure-induced bonding change and structural transformation of $\mathrm{C}_{60} \mathrm{~S}$ are similar in the two samples, both undergoing deformation and amorphization. Nevertheless, the high pressure phases of solvated $\mathrm{C}_{60}$ can indent diamond anvils while that of desolvated $\mathrm{C}_{60}$ s cannot. Further experiments suggest that the solvents in the solvated $\mathrm{C}_{60}$ act as both spacers and bridges by forming covalent bonds with neighbors in 3D network at high pressure, and thus, a fraction of fullerenes may preserve the periodic arrangement in spite of their amorphization.
\end{abstract}


Due to its flexibility in forming $\mathrm{sp}, \mathrm{sp}^{2}$, and $\mathrm{sp}^{3}$ bonds, carbon can adopt a wide range of structures. Depending on experimental conditions, one carbon allotrope can transform into another with dramatically different electronic and mechanical properties. Thus, the conversion mechanisms between various forms of carbon have long been a topic of interest. Thanks to the strong C-C covalent bonds, many carbon phases, including both crystalline and noncrystalline forms, are found to exhibit high hardness and have important technological applications in different fields. The structures and the formation mechanisms of hard carbon phases thus have been subjected to numerous experimental [1-9] and theoretical [10,11] works.

Fullerenes are one type of important precursors for studying the phase diagram of carbon and synthesizing various hard carbon phases.[1-6] At high pressure and high temperature conditions, $\mathrm{C}_{60}$ may transform into $3 \mathrm{D}$ polymer with hardness comparable to that of cubic $\mathrm{BN}$ or into amorphous fullerite phases. Some amorphous phases produced show super- or ultrahardness, such that they can even break diamonds. [2] Cold compression of $\mathrm{C}_{60} \mathrm{~s}$ results in an amorphization of the material above $20 \mathrm{GPa}$ and no superhard phase has been observed even at higher pressures.[12-14] Recently, Wang et al. reported that compression of solvated fullerenes $\left(\mathrm{C}_{60} / \mathrm{m}\right.$-xylene) produces a carbon phase composed of ordered amorphous carbon clusters (OACC).[15] Such formed OACC with a long range periodic structure is challenging the categorization of solid-state materials (including crystalline, amorphous, and quasicrystalline phases). Moreover, this phase exhibits very high hardness and can indent diamond anvils at high pressure. However, the underlying mechanism for such huge differences in the behaviors of these formed phases and the transformation pathways are not clear. Additional information, including clarifying the roles of the solvents on the transformation of the $\mathrm{C}_{60}$ molecules and the nature of the amorphized cell units, is needed to establish the existence of such a transition and to identify the mechanism and the implications for the high-pressure behavior of these unique hard phases in general.

In this work, high pressure Raman spectroscopy has been used to clarify the role of the intercalated solvent on the structural evolution of $\mathrm{C}_{60}$ upon compression by a comparative experiment on solvated and desolvated $\mathrm{C}_{60}$ s crystals. Further Raman studies, laser irradiation, and transmission electron microscopy (TEM) observations on the decompressed samples are used to reveal the nature of the superhard phase at high pressure. 
Solvated $\mathrm{C}_{60}$ single crystals were prepared on a glass substrate by evaporating a saturated $\mathrm{C}_{60} / \mathrm{m}$-xylene solution at room temperature. $[15,16]$ The as-prepared samples contain solvent and have a hexagonal structure $(\mathrm{P} 63, \mathrm{a}=\mathrm{b}=2.37 \mathrm{~nm}$ and $\mathrm{c}=1.012 \mathrm{~nm})$. The solvent was removed by heating samples at $150^{\circ} \mathrm{C}$ under vacuum, transforming it into a FCC structure (here called desolvated sample). The solvated and desolvated samples were loaded separately in a diamond anvil cell (DAC) for high pressure study without using a pressure transmitting medium. High-pressure and room temperature Raman spectra were recorded using a Renishaw 1000 notch filter spectrometer equipped with $830 \mathrm{~nm}$ and $514 \mathrm{~nm}$ exciting lasers. The $\mathrm{R}_{1}$-line emission of a tiny ruby was used for pressure calibration. The structure of the released samples was characterized by TEM (JEOL 2200FS).

Fig. 1 shows the Raman spectra of solvated and desolvated $\mathrm{C}_{60}$ crystals measured using an $830 \mathrm{~nm}$ laser in two separate experiments at ambient and high pressures. The ambient Raman spectra of both samples are similar, with 10 Raman-active modes $\left(2 \mathrm{~A}_{\mathrm{g}}\right.$ and $\left.8 \mathrm{H}_{\mathrm{g}}\right)$ arising from the intramolecular vibrations of $\mathrm{C}_{60}$. The $\mathrm{A}_{\mathrm{g}}(2)$ mode at $1469 \mathrm{~cm}^{-1}$ in the solvated sample suggests a weak van der Waals interaction between solvent and $\mathrm{C}_{60}$. From the recorded spectra up to $44.5 \mathrm{GPa}$, we can see that the Raman peaks of both samples show quite similar pressure evolutions, shifted and weakened with increasing pressure. As the pressure increases, the $\mathrm{A}_{\mathrm{g}}(2)$ intensity decreases while the $\mathrm{H}_{\mathrm{g}}(7)$ intensity increases, implying that the $\mathrm{C}_{60}$ molecules are distorted to a lower symmetry structure.[13,17] The $\mathrm{H}_{\mathrm{g}}$ modes become broad and dominant for both samples in the spectra recorded above $20 \mathrm{GPa}$ while other peaks disappear, suggesting significant deformation and amorphization of $\mathrm{C}_{60}$ molecules.

We further plotted the frequencies of these Raman peaks as functions of pressure. Observations were first focused on the characteristic $\mathrm{H}_{\mathrm{g}}(7), \mathrm{A}_{\mathrm{g}}(2)$, and $\mathrm{H}_{\mathrm{g}}(8)$ modes (Fig. 2), which show quite similar pressure evolutions for the two samples with a clear transition indicated by a change in the slope at $2 \mathrm{GPa}$. The slope change, together with the significant intensity decrease for the Raman peaks with frequencies lower than $800 \mathrm{~cm}^{-1}$ (related to the breathing modes of the $\mathrm{C}_{60}$ cage) at $\approx 2 \mathrm{GPa}$ suggest that a rotational transition of the $\mathrm{C}_{60}$ molecules takes place in the samples.[1,18] Besides the three modes, the plotted curves for other Raman modes of the two samples also show similar pressure evolutions but slightly different pressure coefficients. This should be caused by the slight difference in the compressibility between the two materials due to the presence of solvent in one of the lattices while the dopant has little effect on the transformation of $\mathrm{C}_{60}$ below $20 \mathrm{GPa}$. Above $20 \mathrm{GPa}$, 
the pressure dependence of the $\mathrm{H}_{\mathrm{g}}(7)$ mode exhibits a transition and its frequency becomes almost pressure independent, which is consistent with the low compressibility of the phase formed as determined by X-ray diffraction (XRD) measurements.[15] It is worth noting that when a $514 \mathrm{~nm}$ laser was used for excitation the $\mathrm{H}_{\mathrm{g}}(8)$ mode became dominant above $20 \mathrm{GPa}$, instead of the $\mathrm{H}_{\mathrm{g}}(7)$ mode which dominated when the $830 \mathrm{~nm}$ laser was used.

It is striking that, although the spectroscopic evolutions of the two samples are similar upon compression, the mechanical properties of their high pressure phases are significantly different. The high pressure phase of the solvated sample created clear ring cracks on the diamond anvils but the desolvated sample created only a very small crack on the anvil (note that in another experiment no crack appeared) after a similar compression to $44 \mathrm{GPa}$ (see Fig. 3). This indicates that the transformations of the two materials at high pressure are different due to the solvent intercalation.

To understand the transformations in the materials under pressure, we performed Raman measurements on released samples (Fig. 4). The spectrum of the solvated sample decompressed from an intermediate pressure of $20.5 \mathrm{GPa}$ (at this pressure the material undergoes a transformation) clearly suggests the presence of $\mathrm{C}_{60}$ polymers, with Raman peaks at $950 \mathrm{~cm}^{-1}$, characteristic for $\mathrm{C}_{60}$ polymerization, and $\mathrm{A}_{\mathrm{g}}(2)$ modes downshifted to 1464 and $1459 \mathrm{~cm}^{-1}$ (Fig. 4(a)). Such polymerization was not observed in solvated $\mathrm{C}_{60}$ released from 13 $\mathrm{GPa}$ in Ref. 15. This suggests that the deformation or even collapse of the $\mathrm{C}_{60}$ cages increases at higher pressure, which can overcome the restrictions imposed by the solvent molecules (acting as spacers) and thus allow polymerization. For the sample released from higher pressure (Fig. 4(b)), we see that all these spectra have similar Raman features, i.e., a broad and asymmetric band at $\approx 1500 \mathrm{~cm}^{-1}$ and weaker bands in the $600-750 \mathrm{~cm}^{-1}$ region, suggesting that the high pressure phase can be quenched. This is in agreement with the previous X-ray studies, from which the solvated sample preserves a hexagonal structure at pressure above $60 \mathrm{GPa}$ and upon decompression, while the $\mathrm{FCC} \mathrm{C}_{60}$ sample was amorphized at above $30 \mathrm{GPa}$ and the amorphous phases were quenched to ambient conditions. These two broad Raman bands are generally observed in amorphized fullerite phases containing both $\mathrm{sp}^{2}$ and $\mathrm{sp}^{3}$ bonded carbons.[19,20] We found that, for the high frequency broad band, the most intense peak is at $1470 \mathrm{~cm}^{-1}$ when excited by an $830 \mathrm{~nm}$ laser, while it becomes $1540 \mathrm{~cm}^{-1}$ when using $514 \mathrm{~nm}$ excitation. From in situ high pressure Raman measurements, we can clearly see that the two bands at $1470 \mathrm{~cm}^{-1}$ and $1540 \mathrm{~cm}^{-1}$ evolve from the $\mathrm{H}_{\mathrm{g}}(7)$ and $\mathrm{H}_{\mathrm{g}}(8)$ 
modes, respectively. This is important evidence for the preservation of fullerenes or fullerenelike fragments, consisting of hexagonal and pentagonal carbon rings, in the high pressure phase and in the quenched sample released from $44 \mathrm{GPa}$. Since the $\mathrm{H}_{\mathrm{g}}$ modes are related to bending vibrations of $\mathrm{C}-\mathrm{C}$ bonds in $\mathrm{C}_{60}$ molecules,[17] the broadening of the $\mathrm{H}_{\mathrm{g}}$ bands suggests an amorphization of the $\mathrm{C}_{60}$ molecules under pressure, while the frequency shift of the $\mathrm{H}_{\mathrm{g}}$ modes in the released sample compared with those of the pristine sample is likely due to the covalent bonds formed in the collapsed fragments. Furthermore, in the spectra of the released solvated sample we observe an additional Raman peak at $\approx 1800 \mathrm{~cm}^{-1}$, which probably suggests that the released solvated sample has a structure richer in $\mathrm{sp}^{3}$ carbon.[20]

Remarkably, the Raman spectrum of this $\mathrm{sp}^{3}$-bond rich phase is changed significantly after laser irradiation $(\approx 20 \mathrm{~mW})$ during the Raman measurement (Fig. 4(b)). The two broad bands in the regions $600-750 \mathrm{~cm}^{-1}$ and 1000 to $1750 \mathrm{~cm}^{-1}$ disappear and two new bands at $1321 \mathrm{~cm}^{-1}$ and $1598 \mathrm{~cm}^{-1}$ appear after irradiation. The latter two bands are the typical D- and G-bands observed in $\mathrm{sp}^{2}$-like amorphous carbon.[21,22] The $\mathrm{G}$ band is a doubly degenerate phonon mode $\left(\mathrm{E}_{2 \mathrm{~g}}\right.$ symmetry) at the Brillouin zone center that is Raman active for $\mathrm{sp}^{2}$ carbon networks. The presence of a $\mathrm{G}$ band suggests that the sample contains $\mathrm{sp}^{2}$ carbon networks. The broad D band with a large full width at half maximum (FWHM) of $\approx 200 \mathrm{~cm}^{-1}$ is generally considered to be created by a distribution of clusters with different dimensions and orders in amorphous phases.[21,22] The results suggest that the released amorphous fullerene phase is depolymerized into $\mathrm{sp}^{2}$ carbon rich amorphous carbon clusters. This is different from that of the $3 \mathrm{D}$ polymerized $\mathrm{C}_{60} \mathrm{~s}$ resulting from cold compressing a $2 \mathrm{D} \mathrm{C}_{60}$ precursor, for which free $\mathrm{C}_{60}$ molecules are recovered after laser irradiation.[3]

We further used high resolution TEM (HRTEM) to study the detailed structure of the released samples. Our observations show that the decompressed $\mathrm{C}_{60} / \mathrm{m}$-xylene contains both ordered phases and a number of amorphous areas (see Fig. 5(a)). Selected area electron diffraction (SAED) shows that the diffracted spots from the ordered area can be indexed in a hexagonal structure (Fig. 5(b)). Moreover, from our TEM images, we can see that the individual cell units in the lattice fringe are hard to distinguish, probably reflecting the amorphous character of the cell units (such as molecular deformation/collapse or highly bonded with neighbors). Besides this, in a small number of ordered areas, the cell units in the lattice keep the profile similar to that of the pristine $\mathrm{C}_{60}$ molecules. These results suggest that a large fraction of the 
$\mathrm{C}_{60}$ molecules are amorphized and only a small fraction are still intact after such high pressure compression, in agreement with our Raman results. The desolvated sample decompressed from $44.5 \mathrm{GPa}$ is found to contain amorphous phases and small amount of ordered phase (Fig. 5(c)). Several very weak diffracted spots appear in the SAED pattern and can be indexed by a FCC structure (Fig. 5(d)). This is consistent with the X-ray diffraction measurements in previous work.[14] The results also indicate that the solvent plays role in preserving more ordered phase in the released solvated sample.

Let us now discuss the formation mechanism for the superhard phase in the solvated $\mathrm{C}_{60}$. From Ref. [15], we learn that the transition pressure for $\mathrm{sp}^{2} \mathrm{C}$ into all $\mathrm{sp}^{3} \mathrm{C}$ is above $26 \mathrm{GPa}$ in solvated $\mathrm{C}_{60}$. Such bonding change is probably concomitant with the polymerization of $\mathrm{C}_{60^{-}}$ $\mathrm{C}_{60}$ and $\mathrm{C}_{60}$-solvent. The former is evidenced by the Raman measurement of our sample released from $20 \mathrm{GPa}$ (Fig. 4(a)). Note that in the solvated sample about $10 \% \mathrm{sp}^{2}$ carbon is from the $\mathrm{p}$-aromatic rings of $\mathrm{m}$-xylene. This part should also transform into $\mathrm{sp}^{3}$ carbon by covalent bonding with highly compressed or collapsed $\mathrm{C}_{60}$, which is reasonable since $\mathrm{p}$ aromatic rings of the solvent have high chemical affinity to the fullerene. Subsequently, mxylene acts as a bridge and also spacer to stabilize the periodic structure of the high pressure phase. In this case, part of the amorphized $\mathrm{C}_{60}$ molecules can still be preserved in a periodic arrangement so that the crystalline diffraction of solvated $\mathrm{C}_{60}$ persists even up to $60 \mathrm{GPa}$.[15] Such almost completely covalently bonded carbon in a 3D network, formed by the polymerization of highly deformed or collapsed $\mathrm{C}_{60}$ units at high pressure, has extremely good mechanical properties and may indent the diamond anvils. The $\mathrm{sp}^{2}-\mathrm{sp}^{3}$ transition is partially reversible upon decompression[15] and thus the pristine hexagonal structure is recovered in the released sample. A similar reversible 3D polymerization has also been observed in $\mathrm{Na}_{4} \mathrm{C}_{60}$ under pressure, while in that case $\mathrm{Na}-\mathrm{C}$ ionic bonds were formed and no superhard phase occurred in spite of very low compressibility of the high pressure phase.[20] In addition, our Raman measurements suggest that desolvated $\mathrm{C}_{60} \mathrm{~s}$ undergo similar bonding change to that of solvated $\mathrm{C}_{60} \mathrm{~s}$ upon compression. However, for desolvated $\mathrm{C}_{60} \mathrm{~S}$ crystals, the highly deformed and collapsed $\mathrm{C}_{60}$ molecules may diffuse and merge with neighboring amorphized fragments when a spacer is absent. Thus, the formation of amorphous carbon and dislocation of remaining $\mathrm{C}_{60} \mathrm{~s}$ in the lattice lead to a disordered phase at high pressure and subsequently result in a low mechanical strength in the material. In fact, $\mathrm{FCC} \mathrm{C}_{60}$ crystals are already destroyed and amorphized above $30 \mathrm{GPa} .[13,14]$ 
In summary, we show that the intercalated solvent (m-xylene) has little effect on $\mathrm{C}_{60}$ transformations, while it plays an important role as a bridge and spacer to preserve the stability of deformed or amorphized $\mathrm{C}_{60}$ molecules and allow their polymerization at higher pressure. The high pressure phases of solvated $\mathrm{C}_{60}$ are polymeric structures composed of amorphized fullerene and small amounts of intact $\mathrm{C}_{60} \mathrm{~s}$, which are kept in position by the solvent molecules in the lattice. Thus, a fraction of the fullerenes may preserve the periodic arrangement in spite of their amorphization. Such polymeric carbon forming a 3D network is superhard. The released sample contains both ordered and a number of disordered phases, while laser irradiation reveals that it is mainly composed of amorphous carbon. The results present useful insight into this type of hybrid superhard materials.

This work was supported by the National Basic Research Program of China (2011CB808200), the NSFC (10979001, 11104105, 51025206, 51032001), the Cheung Kong Scholars Programme of China, Changjiang Scholar and Innovative Research Team in University (No. IRT1132). The work was also supported by the Swedish Research Council (621-2010-3732). 


\section{References:}

1. B. Sundqvist, Adv. Phys. 48, 1-134 (1999).

2. V. D. Blank, S. G. Buga, N. R. Serebryanaya, V. N. Denisov, G. A. Dubitsky, A. N. Ivlev,

B. N. Marvrin, and M. Yu. Popov, Phys. Lett. A 205, 208 (1995).

3. K. P. Meletov, G. A. Kourouklis, J. Arvanitidis, K. Prassides, and Y. Iwasa, Phys. Rev. B 68, 094103 (2003).

4. E. V. Tat'yanin, A. G. Lyapin, V. V. Mukhamadiarov, V. V. Brazhkin, and A. L. Vasiliev, J. Phys.: Condens. Matter 17, 249 (2005).

5. M. H. Manghnani, S. Tkachev, P. V. Zinin, X. Zhang, V. V. Brazhkin, A. G. Lyapin, and I. A. Trojan, Phys. Rev. B 64, 121403 (2001).

6. C. A. Davis, G. A. J. Amaratunga, and K. M. Knowles, Phys. Rev. Lett. 80, 3280 (1998).

7. L. Dubrovinsky, N. Dubrovinskaia, V. B. Prakapenka, and A. M. Abakumov, Nat. Commun. 3, 1163 (2012).

8. N. Dubrovinskaia, L. Dubrovinsky, W. Crichton, F. Langenhorst, and A. Richter, Appl. Phys. Lett. 87, 083106 (2005).

9. M. Alvarez-Murga, P. Bleuet, G. Garbarino, A. Salamat, M. Mezouar, and J. L. Hodeau, Phys. Rev. Lett. 109, 025502 (2012).

10. R. L. Zhou and X. C. Zeng, J. Am. Chem. Soc. 134, 7530 (2012), and references therein.

11. F. Zipoli and M. Bernasconi, Phys. Rev. B 77, 115432 (2008).

12. R. S. Kumar, M. G. Pravica, A. L. Cornelius, M. F. Nicol, M. Y. Hu, and P. C. Chow, Diamond Relat. Mater. 16, 1250 (2007).

13. C. S. Yoo and W. J. Nellis, Chem. Phys. Lett. 198, 379 (1992).

14. L. Wang, B. B. Liu, D. D. Liu, M. G. Yao, S. D. Yu, Y. Y. Hou, B. Zou, T. Cui, G. T. Zou, B. Sundqvist, Z. J. Luo, H. Li, Y. C. Li, J. Liu, S. J. Chen, G. R. Wang, and Y. C. Liu, Appl. Phys. Lett. 91, 103112 (2007).

15. L. Wang, B. B. Liu, H. Li, W. G. Yang, Y. Ding, S. V. Sinogeikin, Y. Meng, Z. X. Liu, X. C. Zeng, and W. L. Mao, Science 337, 825 (2012).

16. M. G. Yao, B. M. Andersson, P. Stenmark, B. Sundqvist, B. B. Liu, and T. Wågberg, Carbon 47, 1181 (2009).

17. R. E. Stanton and M. D. Newton, J. Phys. Chem. 92, 2141 (1988).

18. K. P. Meletov, G. A. Kourouklis, D. Christofilos, and S. Ves, Phys. Rev. B 52, 10090 (1995).

19. A. V. Talyzin and L. S. Dubrovinsky, Phys. Rev. B 68, 233207 (2003). 
20. M. G. Yao, V. Pischedda, M. Mezouar, B. Sundqvist, T. Wågberg, R. Debord, and A. San Miguel, Phys. Rev. B 84, 144106 (2011).

21. A. C. Ferrari, Solid State Commun. 143, 47 (2007).

22. K. Sato, R. Saito, Y. Oyama, J. Jiang, L. Cancado, M. Pimenta, A. Jorio, G. G.

Samsonidze, G. Dresselhaus, and M. S. Dresselhaus, Chem. Phys. Lett. 427, 117 (2006). 


\section{Figure Captions:}

FIG. 1. Raman spectra of solvated $\mathrm{C}_{60} / \mathrm{m}$-xylene crystals (black) and desolvated crystals at selected pressures.

FIG. 2. Pressure dependence of the characteristic $H_{g}(7), A_{g}(2)$, and $H_{g}(8)$ modes for the solvated (square) and desolvated (triangle) samples.

FIG. 3. Optical pictures of the diamond anvils after pressure cycles to $44.5 \mathrm{GPa}$ and $44 \mathrm{GPa}$, respectively, for (I) solvated $\mathrm{C}_{60}$ creating a ring crack and (II) desolvated $\mathrm{C}_{60}$ giving a small crack (see arrow). Both culets are $300 \mu \mathrm{m}$ in diameter.

FIG. 4. (a) Raman spectra of solvated $\mathrm{C}_{60}$ crystals released from $20.5 \mathrm{GPa}$. Inset shows the Lorentzian fit to the $\mathrm{A}_{\mathrm{g}}(2)$ modes; (b) Raman spectra of (I) desolvated $\mathrm{C}_{60}$ released from 44.5 $\mathrm{GPa}$; (II) solvated $\mathrm{C}_{60}$ released from $44 \mathrm{GPa}$; (III) solvated $\mathrm{C}_{60}$ released from $35 \mathrm{GPa}$; and (IV) released solvated $\mathrm{C}_{60}$ after laser irradiation. The excitation laser used had a wavelength of $830 \mathrm{~nm}$.

FIG. 5. HRTEM images of decompressed solvated $\mathrm{C}_{60}$, (a) the areas contain order and amorphous phases; (b) SAED pattern from the ordered areas. The structure can be well indexed by a hexagonal structure with calculated d-spacings of $0.89-0.92 \mathrm{~nm}$ for the $(011)$ plane and $0.77-0.79 \mathrm{~nm}$ for the (120)/(111) plane (not shown), as well as d-spacings with low plane index in the range of $0.4-0.5 \mathrm{~nm}$. A weak and broad diffracted ring with the corresponding $\mathrm{d}$ value of around $0.4 \mathrm{~nm}$ that are usually from disorder also appears in the recorded patterns, in good agreement with the XRD measurements in Ref. [15]. (c) HRTEM images and (d) SAED of the decompressed de-solvated $\mathrm{C}_{60}$. The obtained d-spacings of 0.65 $0.7 \mathrm{~nm}$ and $0.45-0.5 \mathrm{~nm}$ (not shown) from SAED can be assigned to (002) and (022) planes in a FCC structure, respectively. 

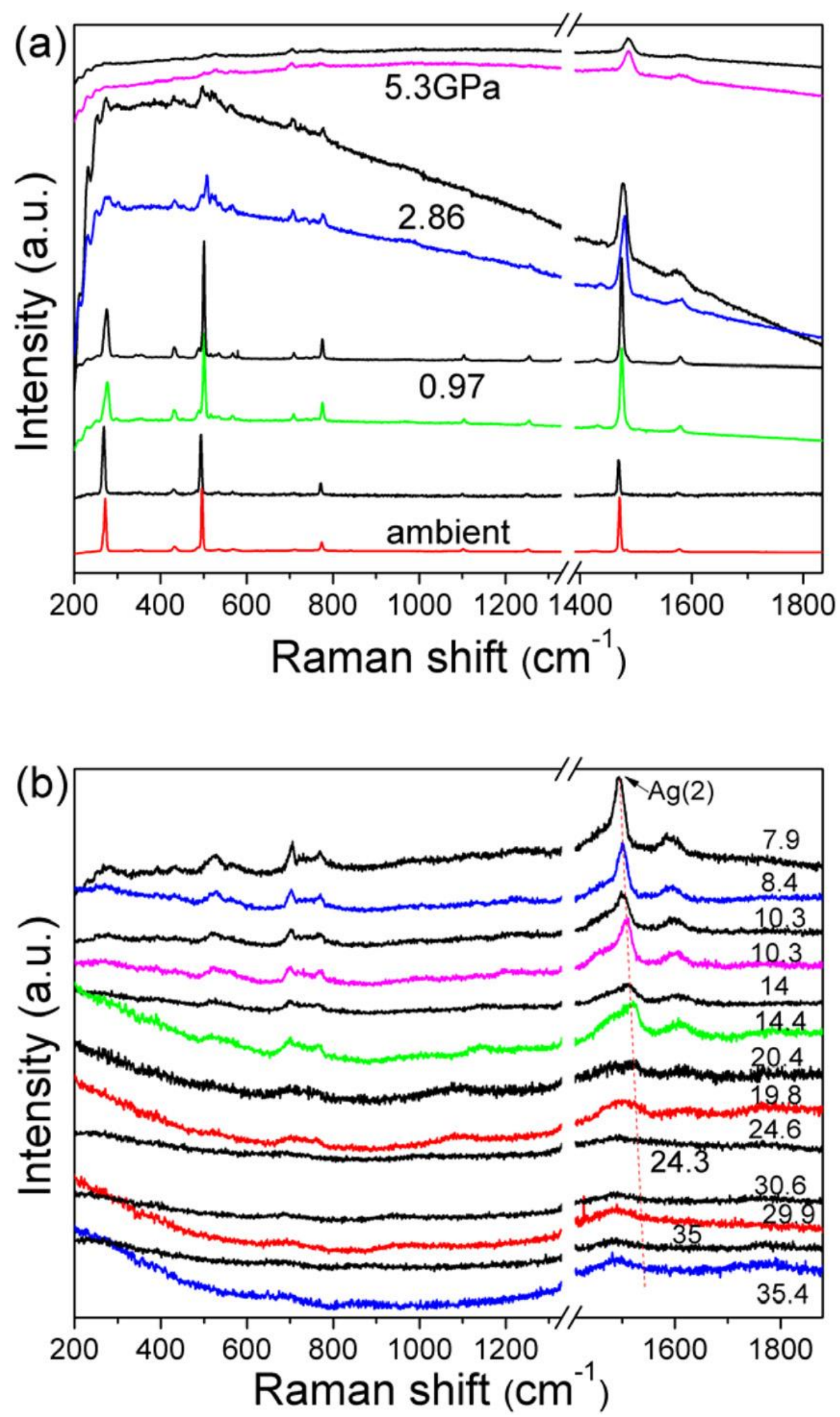

FIGURE 1 


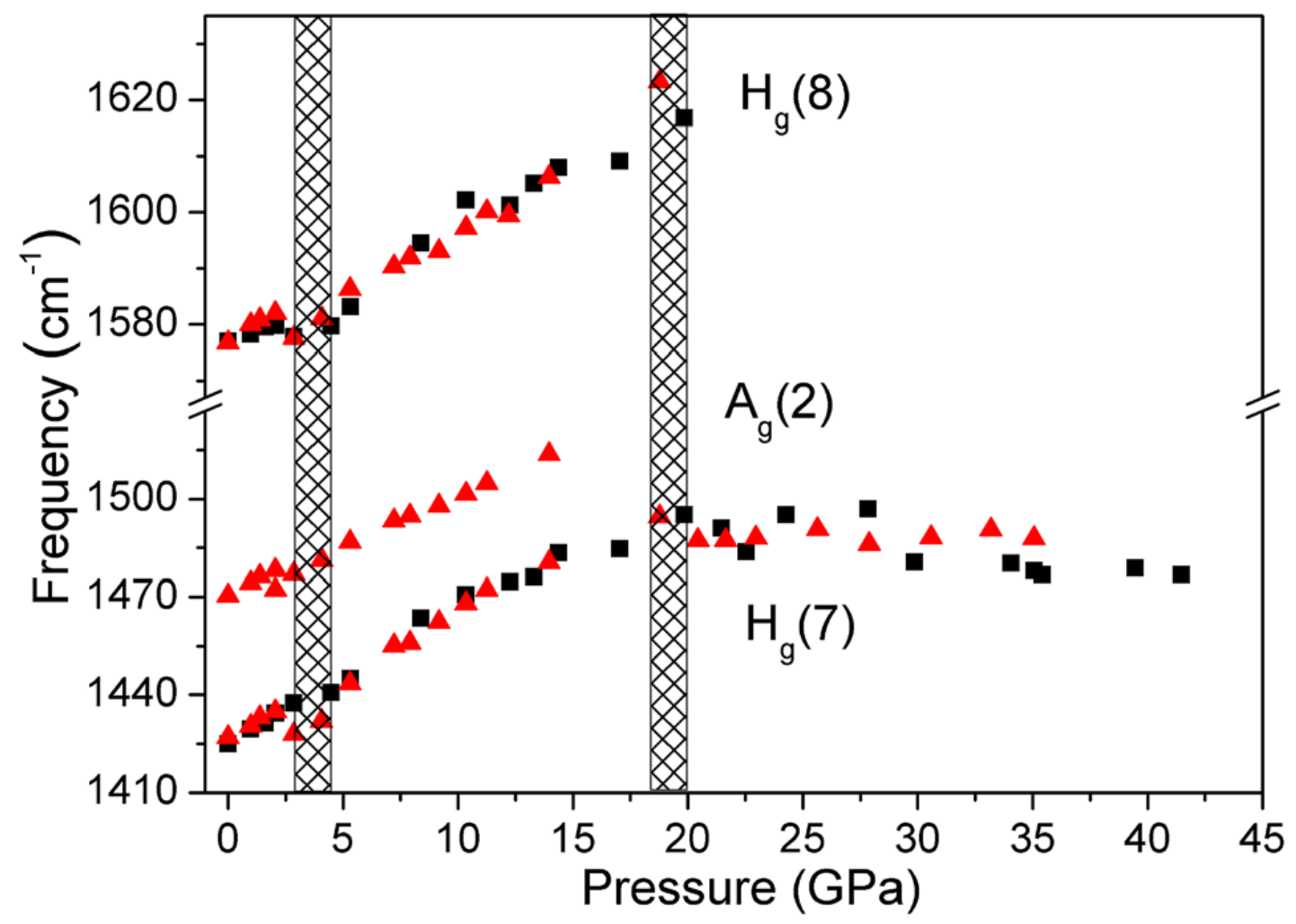

FIGURE 2
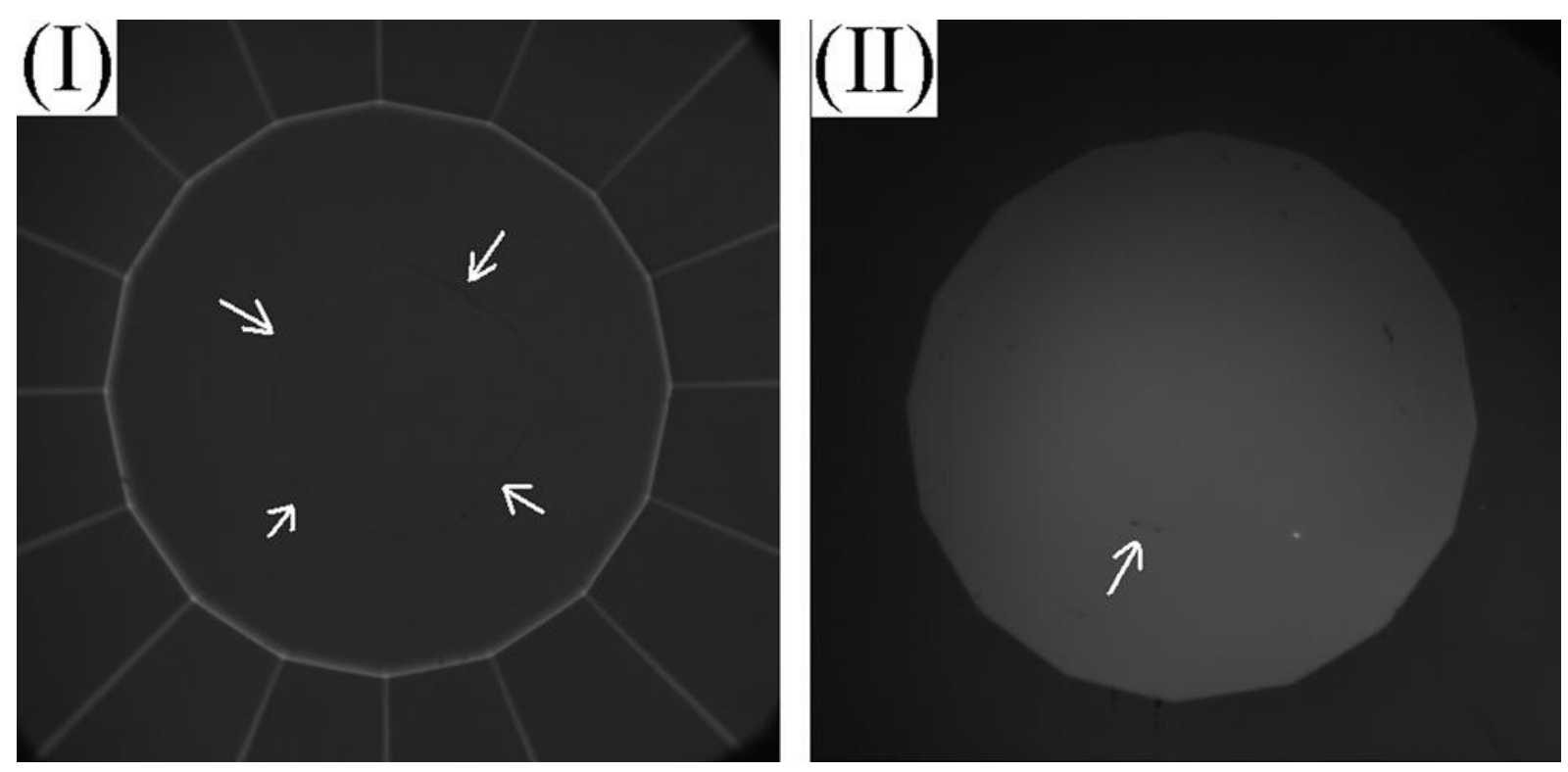

FIGURE 3 

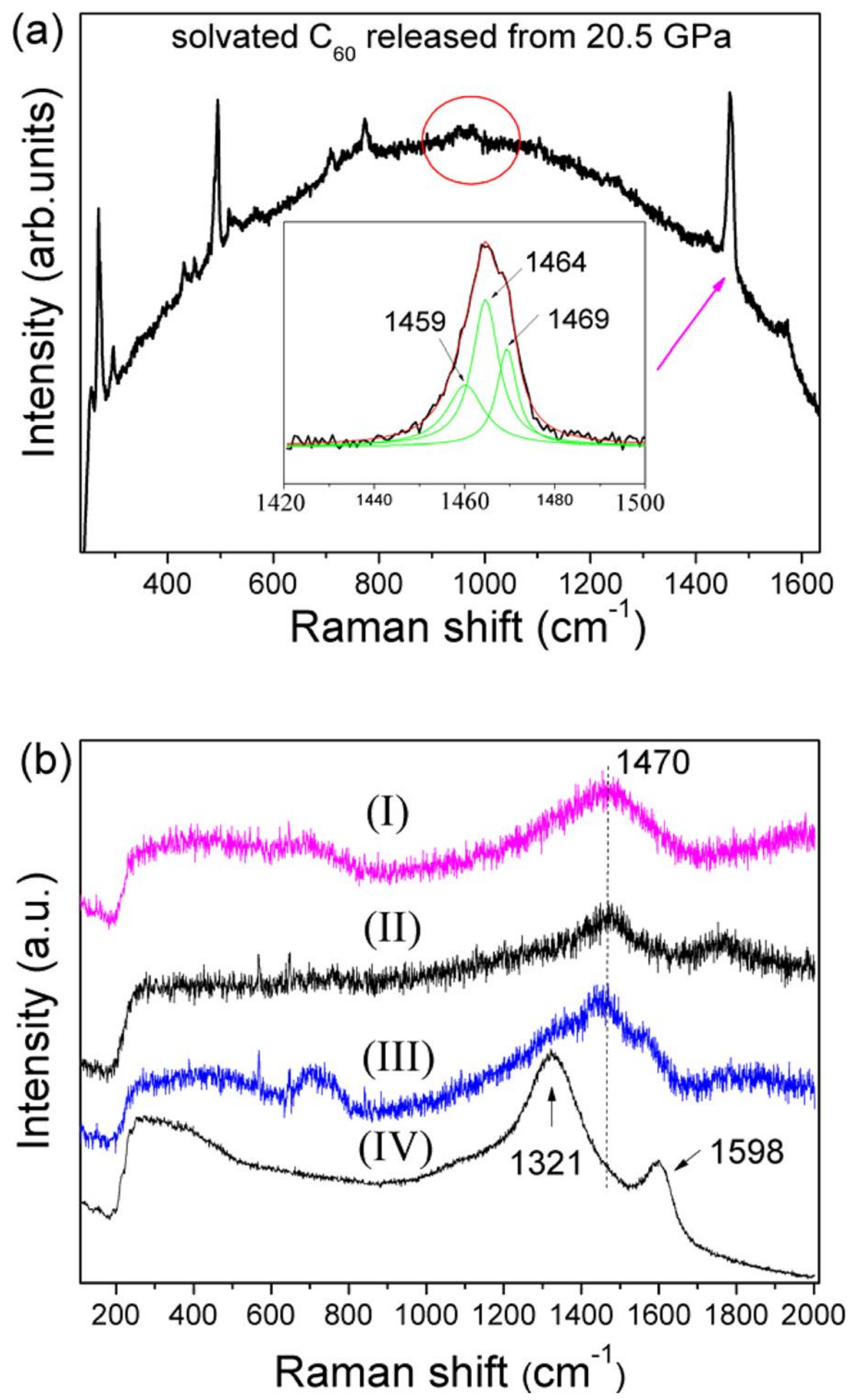

FIGURE 4 


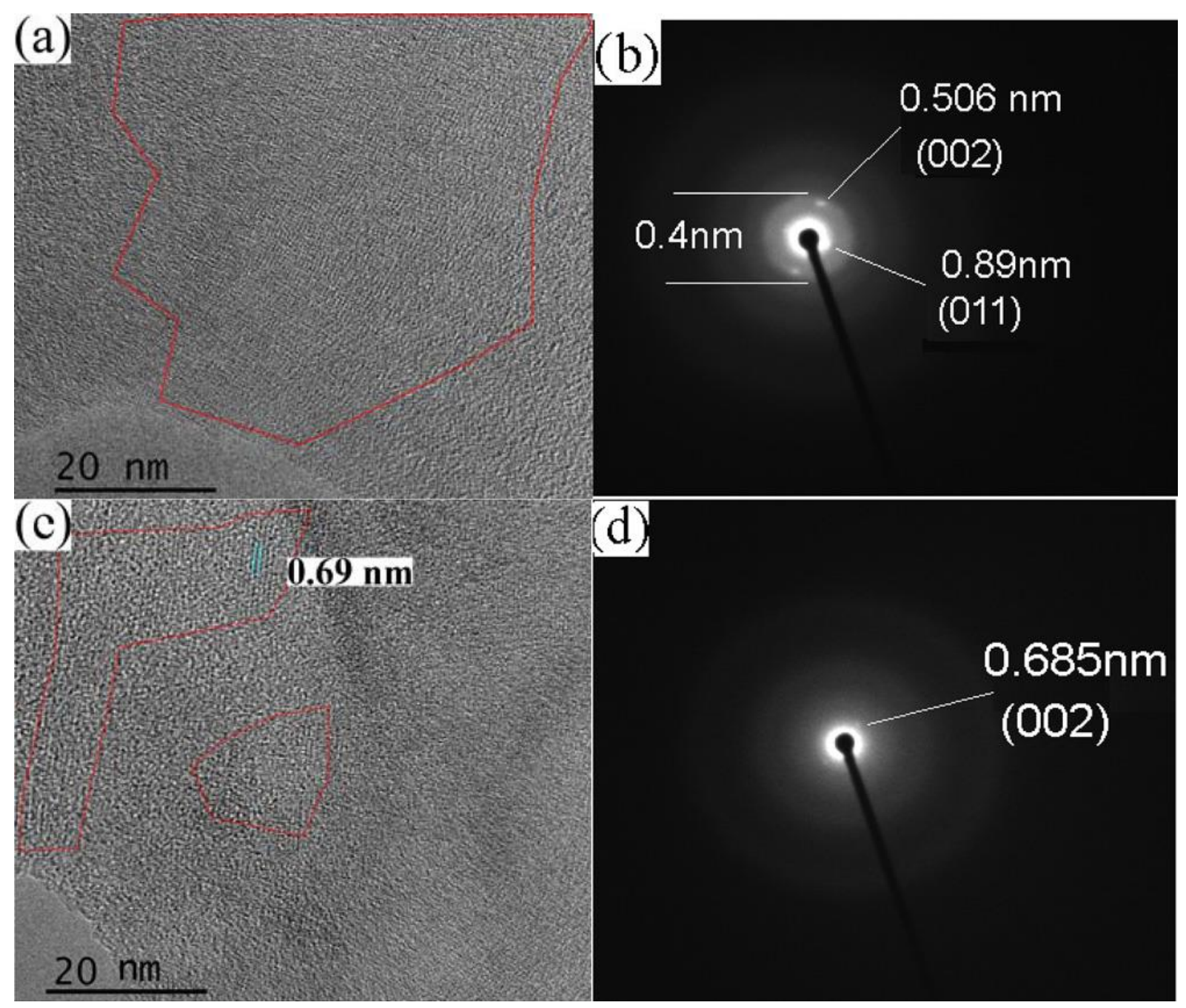

FIGURE 5 